\title{
DESAIN TAS KANTOR WANITA BERBAHAN LEMBARAN SABUT KELAPA (LESKAP)
}

\author{
Hari Purnomo, Dian Janari, Tri Apri Yudianto \\ Jurusan Teknik Industri \\ Universitas Islam Indonesia \\ Jl. Kaliurang KM 14,5 Yogyakarta \\ Email : haripurnomo@uii.ac.id
}

\begin{abstract}
ABSTRAK
Indonesia sebagai Negara yang beriklim tropis memiliki areal perkebunan kelapa luas yang menghasilkan buah, daun dan kayu serta limbah. Limbah sabut kelapa seringkali diabaikan dan tidak dimanfaatkan dengan baik oleh masyarakat. Daging buah adalah komponen utama buah kelapa, sedangkan sabut, tempurung, dan air buah merupakan hasil samping. Sebagian besar petani hanya membuang sabut kelapa atau memanfaatkan untuk kerajinan seperti sapu, keset dan tali tambang. Sabut kelapa jarang dimanfaatkan menjadi produk dengan sentuhan teknologi yang bernilai jual tinggi. Penelitian ini merupakan pemanfaatan limbah serat sabut kelapa dijadikan produk tas kantor wanita dengan teknologi komposit. Lembaran sabut kelapa (leskap) dengan teknologi komposit dilakukan dengan penggabungan serat sabut kelapa dengan karet alam yang di pres selama 30 menit dengan suhu $100^{\circ}$ c. Desain tas dibuat beberapa alternatif yang selanjutnya dilakukan seleksi konsep dan dilakukan penilaian konsep dengan scoring. Hasil seleksi konsep didapat : (a) Konsep desain 5 dijadikan sebagai desain A; (b) Konsep desain 8 dijadikan sebagai desain B; (c) Konsep desain 10 dijadikan sebagai desain C; (d) Konsep desain 3, 6, 7 digabung yang dijadikan desain D. Sedangkan konsep desain 1,2,4 dan 9 tidak diikutkan dalam penilaian konsep. Berdasarkan scoring terpilih konsep desain D dengan nilai 3,0. Spesifikasi tas wanita yang terpilih adalah : (a) Model tas jinjing dan selempang; (b) Warna tas hitam dan coklat; (c) lebar atas $40 \mathrm{~cm}$; (d) lebar bawah $35 \mathrm{~cm}$; (d) Tali tas jinjing dan selempang warna hitam; (f) Tinggi $30 \mathrm{~cm}$; (g) Panjang tali selempang $120 \mathrm{~cm}$; dan (h) Panjang tali jinjing $23 \mathrm{~cm}$.
\end{abstract}

Kata kunci : leskap, seleksi konsep, scoring, tas kantor wanita

\section{PENDAHULUAN}

\section{A. Latar Belakang Masalah}

Indonesia sebagai Negara yang beriklim tropis memiliki berbagai jenis tanaman. Salah satu tananam yang banyak ditanam adalah pohon kelapa yang tumbuh di berbagai penjuru nusantara. Seluruh bagian tanaman kelapa dapat dimanfaatkan mulai dari buah, daun dan kayu (Mahmud dan Ferry, 2005), sedangkan hasil samping seperti sabut kelapa hanya dimanfaatkan untuk produk tradisional seperti keset, sapu dan lain sebagainya (Sudarsono, et al., 2010). Serat sabut kelapa sebagai salah satu serat alami memiliki kelebihan yaitu kuat, elastis, tahan terhadap peruraian mikroba, tahan terhadap salinitas, biodegradable dan banyak tersedia di alam (Wildan, 2010). Pohon kelapa memiliki potensi yang dapat dimanfaatkan dan belum diolah dengan maksimal oleh masyarakat Indonesia terutama limbah sabut kelapa. Sebagian besar petani hanya membuang sabut kelapa atau dimanfaatkan untuk kerajinan. Hasil kerajinan tersebut saat ini tidak diminati oleh masyarakat dan kalah bersaing dengan produk yang lain. Oleh karena itu perlu sentuhan teknologi agar sabut kelapa dapat dimanfaatkan menjadi produk yang bernilai jual tinggi.

Indonesia memiliki lahan kebun kelapa sangat luas dan limbah sabut kelapa belum dimanfaatkan dengan optimal. Total produksi kelapa di Indonesia diperkirakan 14 milyar butir kelapa pertahun, jumlah tersebut menjadikan Indonesia sebagai negara penghasil kelapa terbesar di dunia (Bahtiar, 2012). Setiap butir kelapa mengandung 35\% berat sabut kelapa yang terdiri dari 70\% serbuk serabut kelapa dan 30\% serat kelapa (Amelia dan Siska, 2009). Serat sabut kelapa memiliki daya apung yang tinggi, tahan terhadap bakteri, air garam dan murah. Mutu dari serat sabut kelapa ditentukan oleh warna, persentase kotoran, kadar air dan proporsi antara bobot serat panjang dan serat pendek 
(Sudarsono, et al, 2010). Dengan sifat tersebut serat sabut kelapa dapat dimanfaatkan sebagai bahan komposit yang kuat dan murah. Material komposit adalah gabungan dari penguat dan matriks. Salah satu kekuatan material komposit dipengaruhi oleh jenis serat dan matriks (Gibson, 1994). faktor lain yang berperan serta dalam kekuatan komposit adalah diameter serat, panjang serat, orientasi sudut serat, distribusi serat dan kandungan serat (Amin dan Abdillah, 2009). Kelebihan material komposit dibandingkan dengan logam adalah perbandingan kekuatan terhadap berat yang tinggi, kekakuan, ketahanan terhadap korosi (Nurdin, 2008). Komposit serat merupakan jenis komposit yang hanya terdiri dari satu laminat atau satu lapisan yang menggunakan penguat berupa serat (Sudarsono, et al, 2010). Agar limbah sabut kelapa dapat menjadi produk yang berkualitas dan mempunyai nilai jual tinggi perlu rekayasa dengan teknologi komposit.

Produk dinyatakan berkualitas apabila mampu mengungkap kebutuhan konsumen untuk memenuhi kebutuhannya. Desain yang dapat memenuhi kebutuhan konsumen perlu perencanaan, perancangan maupun pengembangan desain mulai dari tahap menggali ide sampai tahap pengembangan, perancangan, pembuatan prototype, proses produksi, evaluasi dan berakhir dengan tahap pendistribusian (Purba, 2009). Untuk dapat lebih fokus dalam merencanakan produk perlu dilakukan seleksi konsep untuk mendapatkan hasil yang optimal dengan melibatkan stakeholder agar produk sesuai dengan keinginan konsumen dan lebih kompetitif. Seleksi konsep perlu mempertimbangkan metode pemilihan konsep yang efektif dan handal (Ulrich dan Eppinger, 2001). Desain produk baru harus memperhatikan aspek ergonomis agar pengguna merasa nyaman dalam menggunakan. Produk akan nyaman digunakan jika sesuai dengan dimensi tubuh pengguna (Purnomo, 2013). Aplikasi ergonomi secara umum mempunyai tujuan yang hendak dicapai, yaitu menciptakan keadaan fisik dan psikis pekerja yang sehat, dengan mengupayakan desain peralatan, fasilitas dan sistem kerja untuk meningkatkan kinerja, keamanan dan kepuasan pengguna (Wicken, et al. 2004). Berkaitan dengan aspek kenyamanan dan kesehatan, banyak sekali produk yang dipasarkan belum memperhatikan aspek tersebut, sehingga pengguna seringkali mengeluh pada saat menggunakan peralatan dan tidak mampu meningkatkan kinerja yang tinggi. Berdasarkan permasalahan tersebut diatas dapat dinyatakan bahwa penelitian yang terkait dengan pembuatan tas kantor wanita dengan bahan lembaran sabut kelapa (leskap) penting untuk dilakukan sebagai upaya untuk pemanfatan limbah menjadi produk yang bernilai tinggi.

\section{B. Rumusan Masalah} berikut :

Berdasarkan latar belakang di atas dapat dibuat suatu rumusan masalah sebagai

1. Bagaimana desain tas wanita berbahan leskap yang terpilih setelah dilakukan penyaringan konsep?

2. Bagaimana spesifikasi tas wanita berbahan leskap yang terpilih setelah dilakukan penilaian konsep?

\section{METODE PENELITIAN}

\section{A. Pengumpulan Data}

Pengumpulan data dilakukan dengan cara sebagai berikut :

a. Wawancara dengan mengajukan beberapa pertanyaan secara umum untuk mengetahui keinginan dan harapan konsumen terhadap produk tas kantor wanita.

b. Studi pustaka dilakukan untuk menguasai teori maupun konsep dasar yang berkaitan dengan pembuatan desain produk dan sumber referensi serat mendukung terbentuknya landasan teori, sehingga dapat digunakan sebagai landasan dalam penelitian

c. Penyebaran kuisioner untuk menilai alternatif desain yang dibuat untuk dilakukan penyaringan dan penilaian konsep. 


\section{B. Proses Perancangan}

Proses perancangan dilakukan dengan melibatkan secara aktif para stakeholders yang didasarkan pada kebutuhan konsumen. Partisipasi secara aktif pada proses perancangan tas kantor wanita melibatkan ahli ergonomi, pengrajin/teknisi tas, dan pengguna, untuk mempertimbangkan desain yang dibuat. Tahap perancangan ini terdiri dari beberapa langkah. Langkah pertama, pemilihan anggota tim yang terdiri dari satu orang dari teknik mesin, satu orang ahli ergonomi, satu orang pengguna dan perwakilan dari pengrajin/teknisi pembuatan tas. Langkah kedua, Merancang tas kantor wanita dengan berbagai alternatif dengan melakukan diskusi secara rutin berdasarkan pohon klasifikasi yang telah disepakati oleh anggota tim. Langkah ketiga, melakukan evaluasi dan perbaikan terhadap beberapa alternatif desain yang telah dibuat bersama anggota tim.

\section{Pemilihan Desain}

Pada tahap ini dilakukan pemilihan desain dari beberapa alernatif desain tas kantor wanita dengan langkah-langkah sebagai berikut : (1) Langkah pertama, mengumpulkan anggota tim kemudian memberikan penjelasan terkait dengan cara pengisian kuesioner; (2) Langkah kedua, melakukan pengisian kuesioner yang telah disiapkan; (3) Langkah ketiga, mengolah kuesioner yang selanjutnya digunakan untuk menilai alternatif desain yang dibuat. Alternatif desain yang mempunyai skor tertinggi adalah alternatif desain yang terpilih. Alternatif desain terpilih kemudian dirancang sesuai dengan keinginan dan harapan konsumen terhadap produk tas kantor wanita berbahan lembaran sabut kelapa.

\section{Bahan Baku Utama dan Pembantu Pembuatan Tas Kantor Wanita Leskap}

Bahan baku utama yang digunakan untuk pembuatan tas kantor leskap yaitu lembaran sabut kelapa yang diproses dengan teknologi komposit dan kulit sapi muda dengan warna coklat. Penggunaan bahan kulit sapi karena memiliki bebarapa kelebihan yaitu bahan bersifat lunak, tipis, fleksibel dan kuat (Suwardana, 2008), sehingga tas kantor leskap yang dipadu dengan kulit sapi mudah dibentuk dan tahan lama. Sedangkan bahan pembantu yang digunakan untuk memproduksi tas kantor leskap yaitu : (1) spon bon yang berfungsi untuk melapisi atau sebagai penyangga seluruh badan tas bagian dalam agar tas bisa berdiri dan tampak terlihat kaku; (2) selang yang berfungsi sebagai bahan bagian dalam handle untuk membentuk handle menjadi setengah lingkaran; (3) Kain suede sebagai bahan lapis agar produk jadi yang dihasilkan terlihat mewah dan berkualitas; (4) asesoris seperti ring kotak sebagai pengait handle dan keling sebagai pengunci antara handle dan badan tas, untuk menjaga keamanan dari gesekan pada permukaan bagian bawah, perlu dipasangkan sepatu sebagai landasan.

\section{E. Pembuatan Pola Tas dan Perakitan}

Pembuatan pola tas kantor leskap digunakan metode Arah Lipat Pola (ALP). Bahan yang digunakan untuk pembuatan pola yaitu menggunakan kertas malaga dan kertas karton. Peralatan yang digunakan adalah uncek, penggaris, tinta perak, cutter, jangka dan penindih. Proses pembuatan dan perakitan tas kantor leskap di awali dengan membuat desain, pembuatan pola, pemolaan pada bahan material, pemotongan bahan, perakitan, penjahitan dan finishing. Proses pemolaan dalam pembuatan tas kantor leskap dilakukan dengan cara meletakan pola jadi diatas bahan material. Selanjutnya pola digambar diatas permukaan kulit dengan menggunakan tinta perak. Pola jadi diatas bahan kulit diberi besi pemberat, hal ini ditujukan agar dalam proses pemotongan, bahan yang akan dipotong tidak bergeser dan hasilnya akurat. Teknik perakitan menggunakan teknik lem dan jahit yang secara umum sering digunakan para pengrajin. Teknik lem dan jahit pada saat proses perakitan merupakan bagian yang terpenting dalam pembuatan tas kantor. Penggunaan lem dan jahit yang berkualitas akan menghasilkan tas kantor yang mempunyai kualitas tinggi sehingga dapat bersaing di pasaran. 


\section{HASIL DAN PEMBAHASAN}

\section{A. Identifikasi Kebutuhan Konsumen}

Desain tas kantor wanita berbahan leskap dirancang berdasarkan kebutuhan konsumen yang di identifikasi sebagai berikut: (1) mempunyai tampilan yang unik dan elegan; (2) desain yang kuat dan kokoh; (3) menggunakan sistem pengamanan yang baik; (4) nyaman saat digunakan; (5) Bahan leskap awet dan kokoh; (7) Harga terjangkau.

\section{B. Penyaringan Konsep Desain}

Pertimbangan yang digunakan dalam mendesain tas kantor wanita adalah bentuk tas, material tas yang digunakan, dan ruangan dalam tas. Berdasarkan pohon klasifikasi konsep dan hasil wawancara dengan konsumen dan pengrajin maka dapat dibuat sepuluh alternatif konsep desain tas kantor leskap. Sepuluh alternatif konsep desain ditunjukkan pada Gambar 1 berikut :

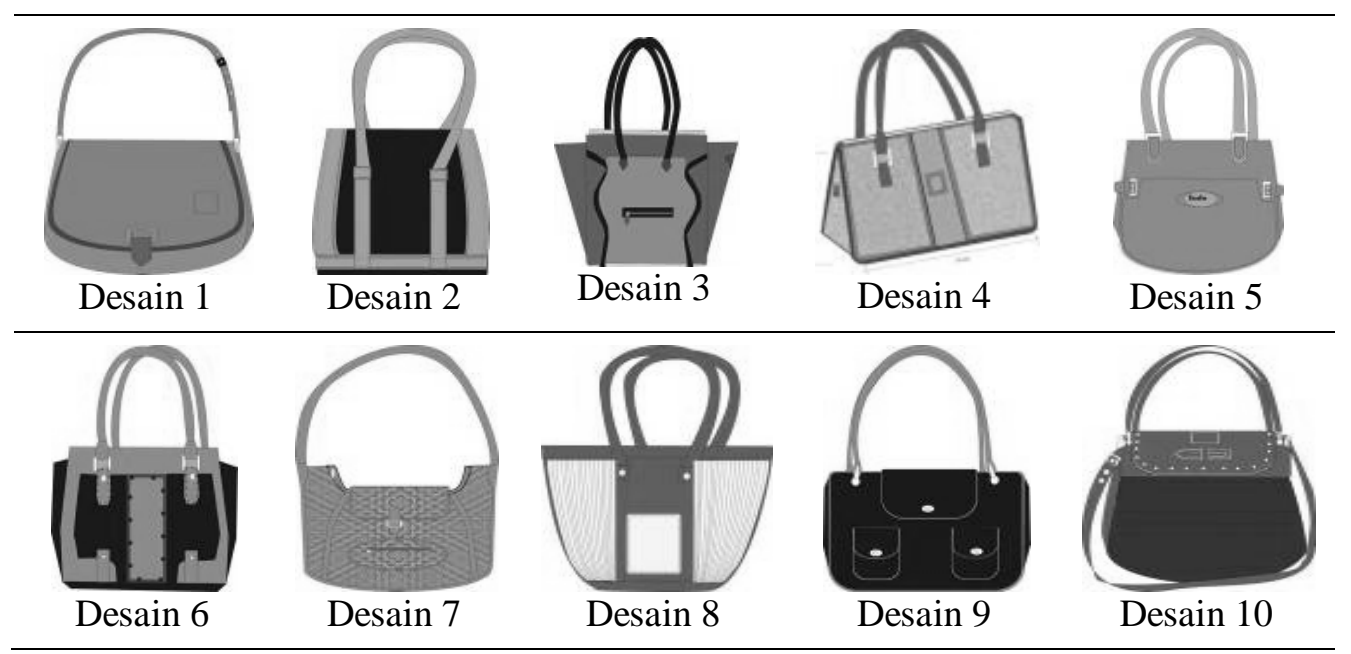

Gambar 1. Desain Tas Kantor Wanita Berbahan Leskap

Berdasarkan sepuluh alternatif desain tas kantor wanita berbahan leskap, selanjutnya dilakukan proses penyaringan desain. Penyaringan ini didasarkan pada penilaian konsumen dan perancang tas. Kriteria seleksi yang digunakan adalah mudah digunakan, awet, mudah diproduksi, multifungsi, nyaman digunakan, memiliki nilai estetika dan mudah dirawat. Hasil penyaringan konsep seperti ditunjukkan pada Tabel 1 berikut :

Tabel 1. Penyaringan Konsep Desain Tas Kantor Leskap

\begin{tabular}{|c|c|c|c|c|c|c|c|c|c|c|}
\hline \multirow{3}{*}{ Kriteria Seleksi } & \multicolumn{10}{|c|}{ Alternatif Konsep Desain } \\
\hline & Tas & Tas & Tas & Tas & Tas & Tas & Tas & Tas & Tas & Tas \\
\hline & 1 & 2 & 3 & 4 & 5 & 6 & 7 & 8 & 9 & 10 \\
\hline Mudah Digunakan & + & - & - & - & + & 0 & + & 0 & - & 0 \\
\hline Awet & - & + & 0 & 0 & 0 & 0 & 0 & - & 0 & 0 \\
\hline Mudah Diproduksi & - & 0 & - & - & + & - & - & 0 & 0 & + \\
\hline Multifungsi & - & - & 0 & - & - & + & - & + & 0 & - \\
\hline $\begin{array}{l}\text { Nyaman } \\
\text { Digunakan }\end{array}$ & - & + & + & - & 0 & 0 & + & 0 & 0 & + \\
\hline Estetika & 0 & 0 & + & + & - & + & + & + & 0 & 0 \\
\hline Mudah Dirawat & + & - & 0 & 0 & + & - & - & 0 & 0 & 0 \\
\hline Jumlah (+) & 2 & 2 & 2 & 1 & 3 & 2 & 3 & 2 & 0 & 2 \\
\hline Jumlah (0) & 1 & 2 & 3 & 2 & 2 & 3 & 1 & 3 & 5 & 4 \\
\hline
\end{tabular}




\begin{tabular}{lcccccccccc} 
Jumlah (-) & 4 & 3 & 2 & 4 & 2 & 2 & 3 & 1 & 1 & 1 \\
\hline Nilai Akhir 2 & -2 & -1 & 0 & -3 & 1 & 0 & 0 & 1 & -1 & 1 \\
Peringkat & 4 & 3 & 2 & 5 & 1 & 2 & 2 & 1 & 2 & 1 \\
\hline Keputusan & $\mathrm{T}$ & $\mathrm{T}$ & $\mathrm{G}$ & $\mathrm{T}$ & $\mathrm{Y}$ & $\mathrm{G}$ & $\mathrm{G}$ & $\mathrm{Y}$ & $\mathrm{T}$ & $\mathrm{Y}$ \\
\hline
\end{tabular}

Keterangan :

$\mathrm{T}=$ Tidak ( Desain tidak digunakan atau ditolak )

$\mathrm{Y}=\mathrm{Ya}$ ( Desain diterima )

$\mathrm{G}=$ Gabungkan ( Desain pada bagian tertentu digabungkan untuk menjadi desain baru ) Hasil penyaringan konsep pada Tabel 1 dapat disimpulkan bahwa :

1. Konsep desain 5 diterima dengan demikian desain 5 dijadikan sebagai desain A untuk dinilai dengan konsep scoring.

2. Konsep desain 8 diterima dengan demikian desain 8 dijadikan sebagai desain B untuk dinilai dengan konsep scoring.

3. Konsep desain 10 diterima dengan demikian desain 10 dijadikan sebagai desain $\mathrm{C}$ untuk dinilai dengan konsep scoring.

4. Konsep desain 3, 6, 7 dilakukan penggabungan desain dengan cara mengambil beberapa bagian konsep desain antara lain : (a) Desain tiga diambil dari bentuk bagian depan tas kantor; (b) Desain enam diambil dari bentuk handle; dan (3) Desain tujuh diambil dari ruangan penyimpanan bagian dalam tas kantor wanita. Berdasarkan pengambilan desain tersebut dijadikan desain baru sebagai desain D untuk dinilai dengan konsep scoring.

5. Konsep desain 1, 2, 4 dan 9 ditolak dan tidak diikutkan dalam penilaian konsep dengan scoring.

Dengan demikian konsep desain menjadi konsep A, B, C dan D seperti ditunjukkan pada Gambar 2 berikut:

\begin{tabular}{l} 
No. Konsep Desain \\
\hline \\
1. Model tas kantor jinjing, ada tempat laptop dan saku \\
2. Warna tas coklat muda dan jingga \\
3. Ukuran : lebar atas, $23 \mathrm{~cm}$ dan bawah, $30 \mathrm{~cm}$ \\
4. Tali tas kantor jinjing warna abu-abu \\
5. Pengaman atas dipasang ritsleting sebagai penutup \\
Konsep B: \\
1. Model tas kantor jinjing, bagian dalam terbagi dua bagian \\
2. Warna tas hitam, coklat dan cream \\
3. Ukuran : lebar atas, 40 cm dan bawah, 20 cm \\
4. Tali tas kantor jinjing warna coklat \\
5. Pengaman atas dipasang ritsleting sebagai penutup
\end{tabular}




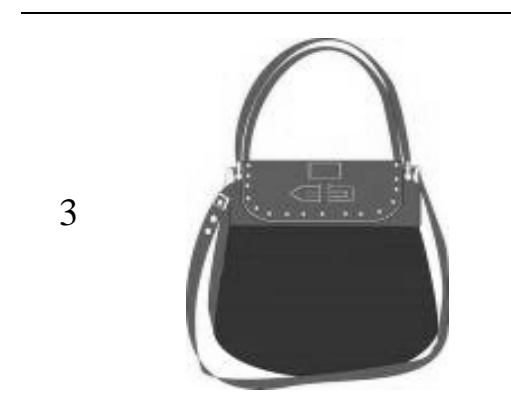

Konsep C:

1. Model tas kantor jinjing dan selempang, bagian dalam terbagi tiga bagian

2. Warna tas hitam dan coklat

3. Ukuran : lebar atas, $24 \mathrm{~cm}$ dan bawah, $30 \mathrm{~cm}$

4. Tali tas kantor jinjing dan selempang warna coklat

5. Pengaman atas dipasang ritsleting dan penutup dengan kunci magnet

\section{Konsep D:}

1. Model tas kantor jinjing dan selempang, ada tempat laptop dan bagian dalam terbagi dua bagian.

2. Warna tas hitam dan coklat.

3. Ukuran : lebar atas, $40 \mathrm{~cm}$ dan bawah, $35 \mathrm{~cm}$

4. Tali tas kantor jinjing dan selempang warna hitam.

5. Pengaman atas dipasang ritsleting dan penutup dengan kunci selipan

Gambar 2. Desain Tas Kantor Wanita Berbahan Leskap Setelah Penyaringan Konsep

\section{Penilaian Konsep}

Penilaian konsep bertujuan memilih alternatif terbaik berdasarkan penilaian dari stakeholders. Penilaian konsep dari desain tas kantor wanita dilakukan dengan konsep scoring, dimana para stakeholders melakukan penilaian dengan memberikan nilai 1 sampai dengan 4 dari 30 responden. Hasil penilaian konsep ditunjukan pada Tabel 2 dimana desain tas kantor terpilih adalah konsep desain $\mathrm{D}$ karena mendapatkan nilai terbesar yaitu 3,03.

Tabel 2. Pemilihan Konsep Desain Tas Kantor Leskap

\begin{tabular}{lcccccccccc}
\hline \multirow{2}{*}{ No } & $\begin{array}{c}\text { Krieria } \\
\text { Pemilihan }\end{array}$ & Bobot & & \multicolumn{2}{c}{ Konsep A } & \multicolumn{2}{c}{ Konsep B } & \multicolumn{2}{c}{ Konsep C } & \multicolumn{2}{c}{ Konsep D } \\
\cline { 3 - 11 } & Rating & $\begin{array}{c}\text { Skor } \\
\text { Bobot }\end{array}$ & Rating & $\begin{array}{c}\text { Skor } \\
\text { Bobot }\end{array}$ & \multicolumn{2}{c}{$\begin{array}{c}\text { Rkor } \\
\text { Bobot }\end{array}$} & $\begin{array}{c}\text { Rating } \\
\text { Skor } \\
\text { Bobot }\end{array}$ \\
\hline 1 & Unik dan elegan & 0,1 & 2,83 & 0,28 & 2,77 & 0,28 & 2,93 & 0,29 & 3,23 & 0,32 \\
\hline 2 & Kuat dan kokoh & 0,4 & 2,57 & 1,03 & 3,03 & 1,21 & 2,93 & 1,17 & 2,93 & 1,17 \\
\hline $\begin{array}{l}\text { Menggunakan } \\
\text { sistem } \\
\text { pengamanan }\end{array}$ & 0,3 & 2,63 & 0,79 & 2,73 & 0,82 & 3,00 & 0,90 & 3,10 & 0,93 \\
\hline $\begin{array}{l}4 \\
4\end{array}$ & $\begin{array}{l}\text { Nyaman } \\
\text { digunakan }\end{array}$ & 0,1 & 2,67 & 0,27 & 2,53 & 0,25 & 2,93 & 0,29 & 3,17 & 0,32 \\
\hline 5 & Awet & 0,1 & 2,77 & 0,28 & 2,70 & 0,27 & 2,97 & 0,30 & 2,87 & 0,29 \\
\hline Total & 1 & & 2,64 & & 2,83 & & 2,96 & & 3,03 \\
\hline
\end{tabular}

\section{Desain Tas Kantor Wanita Terpilih}

Hasil penyaringan dan penilaian konsep dengan metode scoring ditunjukkan seperti pada Tabel 2, sedangkan desain terpilih seperti nampak pada Gambar 3. Pembuatan desain tas kantor wanita berbahan leskap harus memperhatikan bahan baku dan bahan-bahan pendukung lainnya agar dapat sesuai dengan penggunaan tas kantor wanita leskap dengan kualitas tinggi. 


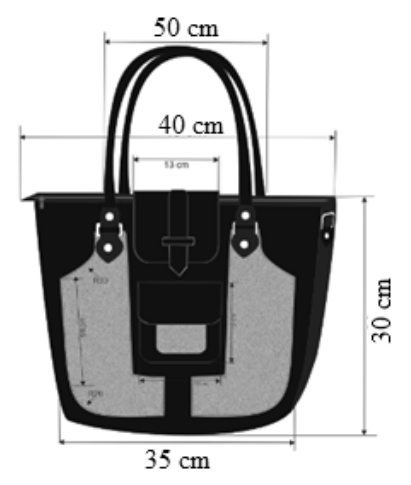

a. Tampak depan
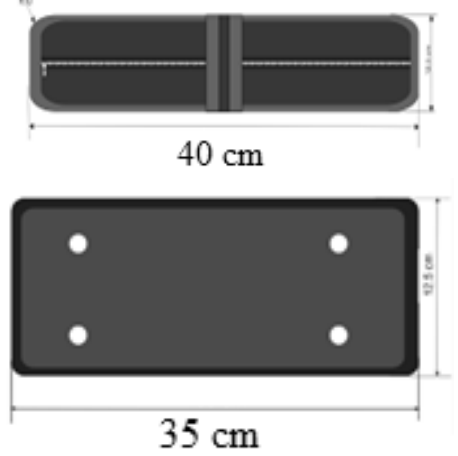

b. Tampak atas dan bawah

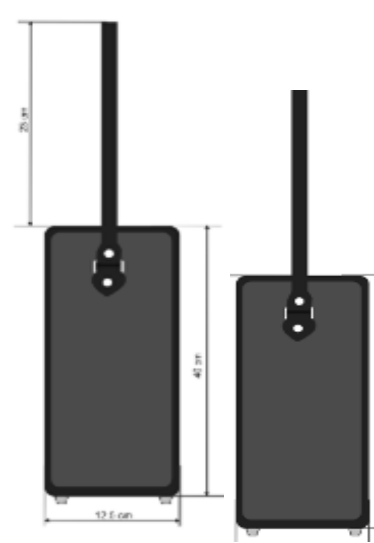

c. Tampak samping kanan dan kiri

Gambar 3. Desain Tas Kantor Wanita Leskap Terpilih

Hasil penilaian konsep desain tas yang terpilih adalah konsep desain D dengan nilai 3,03. Desain tas kantor wanita leskap terpilih mengandung desain yang unik dan elegan karena nampak leskap yang bertekstur. Disamping itu desain tas kantor wanita terpilih nyaman digunakan, hal ini ditunjukkan dengan rating yang tinggi dibandingkan dengan desain lainnya. Model tas wanita terpilih merupakan model tas jinjing dan selempang dengan warna hitam yang dipadu dengan leskap warna coklat yang disertai dengan tutup pengaman pada bagian atas. Ukuran tas kantor wanita adalah lebar atas $40 \mathrm{~cm}$, lebar bawah $35 \mathrm{~cm}$, tinggi $30 \mathrm{~cm}$, panjang tali selempang $120 \mathrm{~cm}$ dan panjang tali jinjing $23 \mathrm{~cm}$.

\section{KESIMPULAN}

Berdasarkan penelitian tentang perancangan tas wanita yang terpilih untuk dinilai dengan konsep scoring adalah : (a) Konsep desain 5 yang selanjutnya dijadikan sebagai desain A; (b) Konsep desain 8 yang selanjutnya dijadikan sebagai desain B; (c) Konsep desain 10 yang selanjutnya dijadikan sebagai desain C; (d) Penggabungan konsep desain 3, 6, 7 menjadi desain D. Hasil penilaian konsep desain tas yang terpilih adalah konsep desain D dengan nilai 3,0. Spesifikasi tas wanita yang terpilih adalah : (a) Model tas jinjing dan selempang; (b) Warna tas hitam dan coklat; (c) lebar atas $40 \mathrm{~cm}$; (d) lebar bawah $35 \mathrm{~cm}$; (d) Tali tas jinjing dan selempang warna hitam; (f) Tinggi $30 \mathrm{~cm}$; (g) Panjang tali selempang $120 \mathrm{~cm}$; dan (h) Panjang tali jinjing $23 \mathrm{~cm}$.

\section{DAFTAR PUSTAKA}

[1] Amelia dan Siska, 2009, Pengaruh Perendaman Panas dan Dingin Sabut Kelapa Terhadap Kualitas Papan Partikel yang Dihasilkannya, Dibaca tanggal 26 November 2012, Tersedia di http://repository.ipb.ac.id/handle/123456789/13725

[2] Amin, M dan Abdillah, F., 2009, Pemanfaatan Limbah Serat Sabut Kelapa Sebagai Bahan Pembuat Helm Pengendara Kendaraan Roda Dua, Laporan Penelitian Universitas Muhammadyah Semarang (UNIMUS).

[3] Bahtiar, 2012, Aplikasi Serat Sabut Kelapa Bermatrik Sagu dan Gliserol Sebagai Pengganti Kemasan Makanan Dari Stereoform, Dibaca Tanggal 17 Juni 2012, Tersedia di http ://www.poltek-kediri.ac.id

[4] Gibson, 1994, Principles of Composite Material Mechanics, New York : CRC Press

[5] Mahmud, Z., dan Ferry, Y., 2005, Prospek Pengolahan Hasil Samping Buah Kelapa, Perspektif Vol.4. No.2. Hal. 55-63. 
[6] Nurdin, H., 2008, Pengaruh Penggunaan Jenis Serat Pada Komposit Polimer Terhadap Kekuatan Tarik, Zona Teknik. Vol.3. No.2. Hal. 143-150.

[7] Purba, H. H., 2009, Inovasi Nilai Pelanggan Dalam Perencanaan \& Pengembangan Produk Aplikasi Samudra Biru dalam Meraih Keunggulan, Yogyakarta: Graha Ilmu.

[8] Purnomo, H., 2013, Antropometri dan Aplikasinya, Yogyakarta. Graha Ilmu.

[9] Sudarsono, Rusianto, T., dan Suryadi, Y., 2010, Pembuatan Partikel Berbahan Baku Sabut Kelapa Dengan Bahan Pengikat Alami (Lem Kopal), Jurnal Teknologi. Vol. 3. No .1. hal: 22-32.

[10] Suwardana, W.I., 2008, Kriya Kulit, Direktorat Pembinaan Sekolah Menengah Kejuruan, Departemen Pendidikan Nasional.

[11] Ulrich, K. T., and Eppinger, S. D., 2001, Perancangan dan Pengembangan Produk, Jakarta: Salemba Teknika.

[12] Wickens, C. D., Lee, J. D., Liu, Y., And Becker, S.E.G., 2004, An Introduction to Human Factors Engineering, New Jersey : Prentice Hall.

[13] Wildan, A., 2010, Studi Proses Pemutihan Serat kelapa Sebagai Reinforced Fiber, Thesis. Universitas Diponegoro Semarang.

\section{UCAPAN TERIMA KASIH}

Ucapan terima kasih ditujukan kepada Kepala Laboratorium Rekayasa Tekstil FTI UII yang telah membantu dalam pembuatan dan pengujian leskap dan kepada Kepala Studio Kulit PPPPTK Seni dan Budaya Yogyakarta yang telah memberikan fasilitas dan arahan dalam pembuatan tas. 